\title{
A CISTERNA QUE CAIU DO CÉU: POLÍTICAS PÚBLICAS E DESENVOLVIMENTO LOCAL NO SEMIÁRIDO BRASILEIRO
}

\author{
THE CISTERN THAT FELL FROM THE SKY: PUBLIC POLICIES AND LOCAL DEVELOPMENT IN THE \\ BRAZILIAN SEMI-ARID REGION
}

LA CISTERNA QUE CAYÓ DEL CIELO: POLÍTICAS PÚBLICAS Y DESARROLLO LOCAL EN EL SEMIÁRIDO BRASILEÑO

\author{
MARTIN JAYO \\ Doutor \\ Universidade de São Paulo - Brasil \\ martin.jayo@usp.br \\ EDUARDO DE LIMA CALDAS \\ Doutor \\ Universidade de São Paulo - Brasil \\ elcaldas@hotmail.com \\ Submetido em: 28/08/2016 \\ Aprovado em: 17/04/2017
}

Doi: alcance.v24n2.p272-284

\section{RESUMO}

Dona Josefa e sua afilhada Aninha residem no município fictício de Riacho Seco, no semiárido brasileiro, e têm uma história pessoal marcada pelas dificuldades impostas pela seca. A partir da história ficcional dessas duas mulheres, o caso de ensino convida o leitor a refletir sobre dois programas reais de política pública voltados à convivência com a seca: o Programa 1 Milhão de Cisternas e o Programa Água Para Todos. Será que Dona Josefa (atendida pelo primeiro) e Aninha (atendida pelo segundo) tiveram suas vidas afetadas da mesma maneira? Ou é possível antever resultados diferentes? 0 caso é construído para que o estudante se coloque no papel do gestor público e compare essas duas alternativas de programa. Ele foi pensado para uso em cursos de graduação, especialização ou mestrado profissional em Administração Pública, Gestão de Políticas Públicas, Gestão Social e Serviço Social, em disciplinas que tenham por objeto a avaliação de políticas públicas e programas sociais. Pode ser usado também em disciplinas que abordem o desenvolvimento em sua dimensão local/territorial.

Palavras-chave: Avaliação de políticas públicas. Continuidade/descontinuidade de políticas públicas. Tecnologia apropriada. Desenvolvimento local.

\begin{abstract}
Dona Josefa (Mrs Josefa) and her goddaughter Aninha live in the fictional town of Riacho Seco, in the Brazilian semi-arid region, and have a personal background marked by the difficulties imposed by water shortage. Through the imaginary story of these two women, this teaching case invites the reader to compare two real public policy programs, both of them aimed at dealing with drought: the "1 Milhão de Cisternas" (One Million Cisterns) and "Água Para Todos" (Water For All) Programs. Were Dona Josefa (benefited from the first) and Aninha (benefited from the second) affected in similar ways, or can we foresee different results? The case is built so that the student can play the role of a public manager and compare these two alternatives. It was designed for use in undergraduate, specialization and professional master's degree courses in Public Administration, Public Policy Management, Social Management and Social Work, in disciplines related to the evaluation of public policies and social programs. It can also be used in disciplines that address the local/territorial dimension of development.
\end{abstract}

Revista Alcance - Eletrônica - vol. 24 - n. 2 - abr.jjun. 2017 
Keywords: Public policy evaluation. Public policy continuity and change. Appropriate technology. Local development.

\section{RESUMEN}

Doña Josefa y su ahijada Aninha viven en la ciudad ficticia de Riacho Seco, en la región semiárida brasileña, y tienen una trayectoria personal marcada por las dificultades impuestas por la sequía. A partir de la historia ficcional de esas dos mujeres, este caso para la enseñanza invita al lector a reflexionar sobre dos programas reales de política pública orientados a la convivencia con la sequía: el Programa 1 Millón de Cisternas y el Programa Agua Para Todos. ¿Es posible que Doña Josefa (atendida por el primero) y Aninha (por el segundo) hayan tenido sus vidas afectadas de la misma manera, o se pueden antever resultados distintos? El caso está construido de forma a que el estudiante se ponga en el lugar del gestor público y compare esas dos alternativas de programa. Ha sido diseñado para su uso en cursos de grado, especialización o maestría profesional en Administración Pública, Gestión de Políticas Públicas, Gestión Social o Servicio Social, en asignaturas que tengan por objeto la evaluación de políticas públicas y programas sociales. También puede ser utilizado en disciplinas que aborden el desarrollo en su dimensión local/territorial.

Palabras clave: Evaluación de políticas públicas. Continuidad/discontinuidad.

\section{INTRODUÇÃO}

- Madrinha, chegou a minha cisterna!

- Como assim, Aninha? Não foi você que fez?

- Fui eu não, madrinha! Eu não sei fazer cisterna. Ela veio de caminhão. É todinha de plástico!

- Que bom, Aninha. Agora cuida direitinho, que ela dura muito tempo. A minha até hoje não deu problema. Se bem que ela é de cimento e fui eu mesma que construí. Essa de plástico eu não sei como é não...

- Té logo, madrinha, bênção!

- Deus te abençoe! Depois eu quero saber melhor que cisterna é essa que cai assim do céu.

Estamos em março de 2012, e esse foi um encontro casual entre Dona Josefa, 58 anos, moradora do povoado Nascente, no município de Riacho Seco, e Aninha, sua afilhada de 27 anos, que mora com os filhos pequenos em uma casa próxima ao povoado. As duas estão sempre ocupadas e não costumam se visitar com frequência, mas encontros como este fazem com que se mantenham sempre em contato.

Dona Josefa sai contente do encontro, mas ao mesmo tempo um pouco desconfiada. Há cerca de três anos, ela foi atendida por um programa governamental que transformou substancialmente sua vida, ao lhe ajudar a construir uma cisterna para armazenar água em casa durante os longos períodos de seca. Desde então, feliz com o resultado, ela não via a hora de Aninha ser atendida também. Mas agora que essa boa notícia chega, ela não sabe muito bem o que pensar. Pelo jeito o programa mudou bastante. Será que essa cisterna da afilhada é tão boa como a dela?

\section{O MUNICÍPIO DE RIACHO SECO}

Riacho Seco é um município nordestino de 5 mil habitantes, localizado na região conhecida como Polígono da Seca, ou Semiárido ${ }^{1}$. Sua população está distribuída entre a sede do município e 40 núcleos rurais

\footnotetext{
${ }_{1}$ Polígono da Seca é uma antiga designação territorial, criada por Lei em 1936, como área a ser atendida por políticas governamentais de combate às secas. Em 1989 o Polígono teve sua designação oficial alterada para Região Semiárida, e sua última delimitação oficial data de 2004. A área abrange quase 1 milhão de quilômetros quadrados, compreendendo 
(povoados) espalhados pelo território. Na sede do município estão o pronto-socorro, a única unidade escolar de ensino médio, um correspondente bancário, a delegacia de polícia, alguns imóveis que sediam secretarias e departamentos do poder público municipal, a Câmara Municipal e cerca de 60 estabelecimentos comerciais, entre mercadinhos, farmácia, lojas de sapatos, ferramentas e roupas.

Cada núcleo rural (povoado) é constituído por um conjunto de residências, e alguns deles têm 4 ou 5 estabelecimentos comerciais e unidades escolares multisseriadas. Há também, em Riacho Seco, aproximadamente 100 casas que não estão localizadas nem na sede do município e nem nos núcleos rurais. Estão dispersas no território. Aninha mora em uma delas. Dona Josefa, no povoado Nascente.

A história do município é marcada pelos fluxos migratórios, diretamente relacionados com os períodos mais intensos de seca.

\section{OÊXODO}

A família de Dona Josefa é de Riacho Seco, e ela tem lembrança de quando seu avô materno deixou o município para colher café no estado de São Paulo. Também se lembra da retirada de seis dos seus oito tios maternos, e de todos os tios paternos. O pai de Josefa foi um dos poucos homens da família que permaneceu no município.

A história se repete geração após geração, não só em Riacho Seco, mas em todo o semiárido. Os homens viajam para alguma frente de trabalho, principalmente na região Sudeste. Em geral vão trabalhar na construção civil, ou nas colheitas de café, cana-de-açúcar e laranja. Alguns se acostumam com o movimento pendular periódico de se retirar para voltar com algum dinheiro para o sustento da família. Outros se adaptam à vida na periferia de grandes cidades e por lá constituem novas famílias. Há ainda os que não voltam para seus lugares de origem, mas também não se estabelecem em grandes centros urbanos. Passam a fazer parte do contingente de operários que permanecem morando às margens das rodovias que foram construir, ou nos bairros precários no entorno das obras em que foram operários.

As mulheres que ficam nas cidades de origem cuidam dos filhos. 0 trabalho diário de buscar água é extenuante. Em geral ajudadas pela prole, elas caminham 10 ou mesmo 15 quilômetros carregando latas e cacimbas vazias, para voltar com os recipientes cheios. Os açudes, mesmo sendo feitos com recursos públicos, muitas vezes estão em propriedades privadas. Além da rápida evaporação da água assim armazenada, a entrada na propriedade nem sempre é fácil, fazendo do açude uma alternativa nem sempre pertinente.

Em períodos próximos das eleições municipais ou estaduais, a dificuldade de acesso à água facilita práticas clientelistas de troca de água por votos. Os candidatos que se perpetuam no poder, e que geralmente são os proprietários das terras onde estão os açudes, têm o costume de distribuir água por meio de caminhões-pipa. Convencionou-se chamar essas práticas de indústria da seca.

\section{DO COMBATE À CONVIVÊNCIA}

O combate à seca na região semiárida foi objeto de políticas públicas federais ao logo de todo o século 20, podendo-se apontar como marcos importantes a criação da Inspetoria de Obras Contra as Secas (IOCS), em 1909, do Departamento Nacional de Obras Contra a Seca (DNOCS), em 1945, da Superintendência de Desenvolvimento do Nordeste (SUDENE), em 1959, entre outros. Em todo esse tempo, no entanto, as políticas não foram capazes de surtir efeitos para a população local. Hegemonizadas pela elite, baseadas fundamentalmente na construção de grandes reservatórios de águas fluviais (açudes) em terras privadas, que beneficiaram mais os fazendeiros e os coronéis do que a população, e complementadas por ações assistenciais (distribuição de caminhões-pipas, cestas básicas, etc.), elas não trouxeram mudanças estruturais ou melhoras de longo prazo para a região, que se acostumou a ver a fome, o êxodo e a indústria da seca como parte de sua própria identidade.

1133 municípios nos estados de Alagoas, Bahia, Paraíba, Pernambuco, Piauí, Rio Grande do Norte, Sergipe, Ceará e norte de Minas Gerais. Tem aproximadamente 22 milhões de habitantes, $12 \%$ da população brasileira. 
Pode-se dizer, no entanto, que em 1999 surgiu um novo paradigma nas políticas públicas para a região. Nesse ano, 61 organizações da sociedade civil, reunidas em Recife por ocasião de uma convenção da Organização das Nações Unidas (COP3 - $3^{\mathrm{a}}$ Conferência das Partes da Convenção de Combate à Desertificação e à Seca), assinaram a Declaração do Semiárido Brasileiro, que propunha uma nova orientação estratégica para as políticas públicas na região do semiárido: a ideia de combate à seca era substituída pela ideia de convivência com o semiárido, e as grandes obras davam lugar à ação local.

É nesta ocasião que surge a Articulação do Semiárido (ASA), uma rede de cerca de 700 organizações da sociedade civil voltada ao desenvolvimento de políticas de convivência com a região semiárida. Em 2003, a ASA lançou um projeto inovador: o Programa 1 Milhão de Cisternas (P1MC), considerado a maior mobilização da sociedade civil da história brasileira na luta contra a seca.

\section{O PROGRAMA 1 MILHÃO DE CISTERNAS (P1MC)}

O clima da região semiárida se caracteriza por uma curta temporada de chuvas, concentrada em 2 ou 3 meses do ano, seguida de um longo período de forte estiagem. As cisternas desenvolvidas pelo P1MC nada mais são do que reservatórios domiciliares, capazes de captar quantidade suficiente de água na época das chuvas e armazená-la para consumo no período de estiagem.

O artefato é uma estrutura cilíndrica semienterrada, construída com placas de cimento, que é instalada a poucos metros da casa e se interliga ao telhado desta por meio de um tubo de PVC e calhas de zinco. Por essa rede coletora, a água de chuva captada pelo telhado escorre até o reservatório, onde ficará armazenada para consumo. A capacidade padrão de uma cisterna é de 16 mil litros, equivalente ao consumo de uma família de 5 a 6 pessoas durante os 8 meses de estiagem. 0 interior da cisterna é vedado e protegido da luz, de forma a impedir a proliferação de algas e manter a água própria para consumo humano.

A tecnologia construtiva das cisternas do P1MC não requer habilidades técnicas sofisticadas e pode ser facilmente transferida. Os materiais utilizados são igualmente simples: cimento, areia, brita, arame, calhas de zinco e tubos de PVC, todos eles adquiridos nos próprios municípios beneficiados pelo programa, de forma a dinamizar a economia local. A vida útil de uma cisterna é estimada em 40 anos, e seu custo de manutenção é pouco significativo. $O$ custo da construção, porém, que gira em torno de $R \$ 1.800,00$ por cisterna, excede a capacidade financeira das famílias atendidas, exigindo que o programa seja financiado por doações privadas ou recursos governamentais.

Um Termo de Parceria foi firmado em 2003 entre a Associação Programa 1 Milhão de Cisternas (AP1MC) e o Ministério do Desenvolvimento Social (MDS), dotando o programa de orçamento e conferindo-lhe feições de política pública. O MDS estabeleceu, como meta, instalar 1 milhão de cisternas em cinco anos, isto é, até 2008. Foi assim que a cisterna de Dona Josefa foi construída.

\section{A CISTERNA DE DONA JOSEFA}

Riacho Seco foi incluído em 2007 no rol de municípios atendidos pelo PM1C, em função de seus indicadores sociais: índice de desenvolvimento humano (IDH), número de crianças e adolescentes e alta taxa de mortalidade infantil, entre outros. Uma equipe da ASA esteve no município e fez uma proposta: eles capacitariam os moradores para a construção das suas cisternas e se responsabilizariam pelo custo do material. Caberia à própria comunidade local, por meio de um Conselho Municipal de gestão do programa, escolher quais moradores do município seriam atendidos.

Pouco tempo depois, fazia-se um mutirão: Dona Josefa ajudou a construir as cisternas de outros moradores do povoado Nascente e, chegada a sua vez, teve ajuda destes para fazer a sua própria. As famílias atendidas no povoado tinham sido escolhidas pelo Conselho Municipal do programa, de acordo com cinco critérios: número de crianças e adolescentes na escola, número de crianças de 0 a 6 anos de idade, número de pessoas maiores de 65 anos, domicílios com mulher chefe de família, e presença no domicílio de pessoas com necessidades especiais.

Cada cisterna, semelhante às retratadas nas fotografias do Anexo 1, levou cinco dias, em média, para ficar pronta. Em algumas semanas, várias casas do povoado já estavam equipadas. Foi cansativo, mas Dona 
Josefa até hoje se admira. Lembra-se de sua mãe e de tantas outras mulheres que conheceu, que padeceram a vida inteira na luta pela água, sem imaginar que poderia ser diferente. Pensa em quanto sofrimento poderia ter sido poupado por uma solução tão engenhosa, e no fundo tão simples...

Nesse processo, Dona Josefa aprendeu técnicas de construção e também aprendeu a conservar e reparar a sua própria cisterna. Conhecendo por experiência própria a dureza da busca de água, ela é solidária com os vizinhos e conhecidos que ainda não construíram suas cisternas, compartilhando a água da sua própria. $\mathrm{Na}$ construção de cisternas, Dona Josefa fez novos amigos, começou a discutir política e a compreender a indústria da seca. Dona da sua água e sem depender mais de favores para ter acesso a ela, percebeu que não é tão difícil conviver com o semiárido e se desenvolver nele. Montou com os vizinhos um banco de sementes e se dedica à agricultura familiar, empregando nisso parte do tempo e da energia que antes dispendia na dura rotina de ir buscar água longe de casa. Se usada racionalmente, a água da cisterna é suficiente para matar a sede da família, da plantação e de uma pequena criação. Tornou-se uma entusiasta do projeto.

Apesar disso, ela deixou de acompanhar as articulações promovidas pela ASA e pelo governo com outros moradores mais distantes. Talvez, em decorrência dessa participação e da compreensão da importância do processo de construção da cisterna, não tenha compreendido por que sua afilhada Aninha disse que recebeu uma cisterna pronta, em vez de participar de um processo de mutirão, como ocorrera com ela própria.

\section{A CISTERNA DE ANINHA}

Em dezembro de 2011, o Governo Federal reformulou a política. Rompeu a parceria entre o MDS e a ASA e desistiu do modelo de cisternas de cimento do P1MC. A alegação era que a parceria não tinha conseguido cumprir suas metas. Era preciso acelerar a instalação de cisternas e para tanto o governo lançava uma nova iniciativa: o Programa Água Para Todos, implementado por meio do Ministério da Integração Nacional. O governo tinha interesse em ganhar agilidade e anunciava a intenção de universalizar o acesso à água de consumo e produção no semiárido.

De fato, a parceria entre ASA e MDS não tinha conseguido construir o número de cisternas anunciado em 2003. Um levantamento da ASA, feito em fevereiro de 2013, revela que o P1MC havia construído até então 419.178 cisternas - pouco mais de $40 \%$ da meta de 1 milhão prevista para 2008.

A meta anunciada pelo Programa Água Para Todos era ambiciosa, se comparada aos números conseguidos até então: instalar 750 mil cisternas até dezembro 2014. Para tornar isso possível, o governo substituiu o tipo de cisterna empregado. Em vez de construídas localmente com o envolvimento e a capacitação da população, as cisternas passariam a ser produzidas industrialmente em poliuretano e adquiridas de forma centralizada pelo Ministério. Isto de um lado elevava o custo unitário, de $\operatorname{R} \$ 1.800,00$ para cerca de $\mathrm{R} \$ 5.000,00$ por cisterna instalada, mas de outro permitiria um grande ganho de escala. Foi assim que Aninha foi atendida.

No início de 2012, a casa de Aninha foi selecionada pelo Comitê Gestor Municipal do Programa para ter uma cisterna instalada². Como já sabia que a madrinha tinha ficado muito satisfeita, não teve dúvidas: topou na hora. Ficou sabendo que só precisaria participar de uma reunião na Prefeitura e depois frequentar um curso rápido, junto com outros moradores beneficiados, sobre como usar a cisterna. Depois disso, era só esperar, que a cisterna chegaria.

E chegou mesmo, de manhã bem cedo, faltando poucos dias para São José (19 de março), bem no comecinho da temporada de chuvas. 0 caminhão do Ministério da Integração Nacional trazia quatro grandes cisternas de poliuretano semelhantes às retratadas nas fotografias do Anexo 2: de cor cinza, com a logomarca do Programa Água Para Todos impressa em tinta branca. Em poucas horas a de Aninha já estava instalada, e os técnicos partiram para outras casas, para instalar as seguintes.

Aninha ficou contente. A cisterna não era igual à da madrinha, mas a não ser pela aparência e pelo material de que era feita, ela parecia ser exatamente a mesma coisa.

Seria mesmo?

\footnotetext{
20 Comitê Gestor Municipal é uma proposição do P1MC incorporada ao Programa Água Para Todos. A atuação do Comitê e os critérios de seleção das famílias a serem atendidas com cisternas de poliuretano são semelhantes aos que se verificam no P1MC para a construção de cisternas de cimento.
} 


\section{Anexo 1}

\section{Cisternas como a de Dona Josefa}
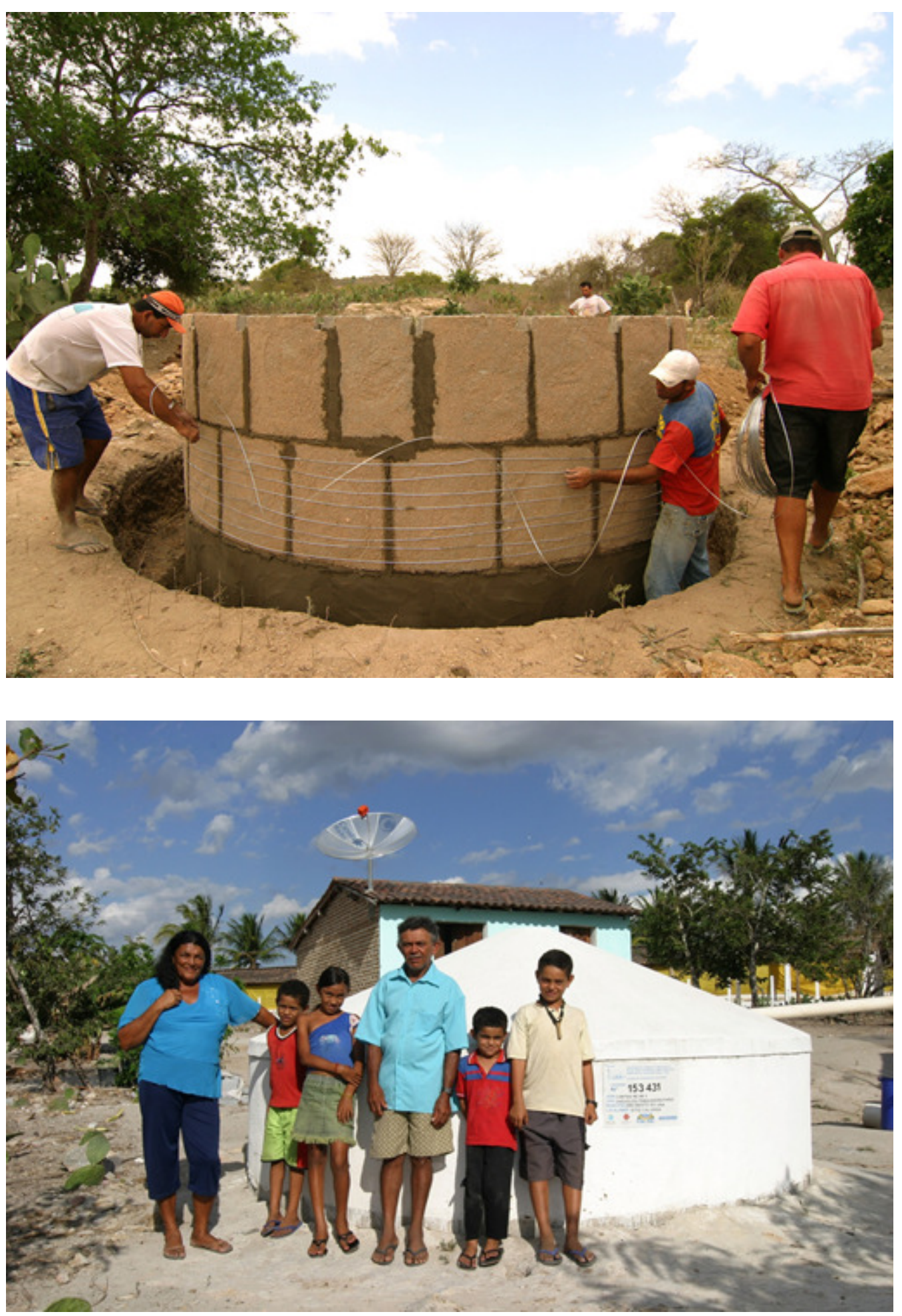

Fonte: Imagens reproduzidas do site da Articulação do Semiárido (http://asabrasil.org.br) 


\section{Anexo 2}

Cisternas como a de Aninha
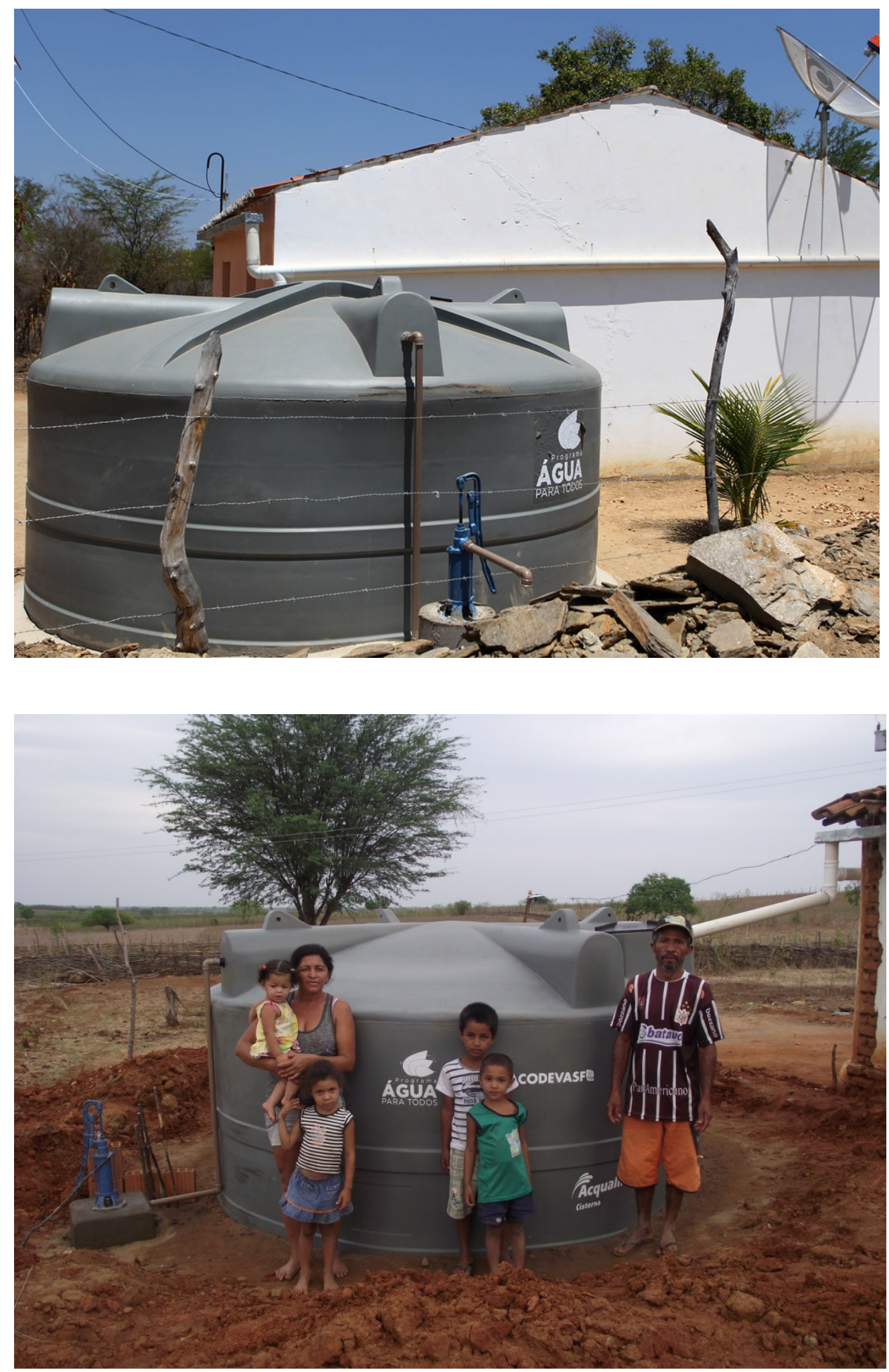

Fonte: Imagens reproduzidas do Site do Ministério da Integração Nacional (http://www.integracao.gov.br) 


\section{NOTAS DE ENSINO}

\section{Sinopse do Caso}

Dona Josefa e sua afilhada Aninha residem no município fictício de Riacho Seco, no semiárido brasileiro, e têm uma história pessoal marcada pelas dificuldades impostas pela seca. A partir da história ficcional dessas duas mulheres, o caso convida o leitor a refletir sobre dois programas reais de política pública, voltados à convivência com a seca: o Programa 1 Milhão de Cisternas e o Programa Água Para Todos. Será que Dona Josefa (atendida pelo primeiro) e Aninha (atendida pelo segundo) tiveram suas vidas afetadas da mesma maneira? Ou é possível antever resultados diferentes? 0 caso é construído de tal forma que o estudante se coloque no papel do gestor público e compare essas duas alternativas de programa.

\section{Aplicação}

O caso foi pensado para ser aplicado em cursos de graduação, especialização ou mestrado profissional em Administração Pública, Gestão de Políticas Públicas, Gestão Social e Serviço Social, em disciplinas que tenham por objeto a avaliação de políticas públicas e programas sociais. Pode ser usado também em disciplinas que abordem o desenvolvimento em sua dimensão local/territorial.

\section{Objetivos Educacionais}

O objetivo geral deste caso de ensino é desenvolver no estudante capacidades voltadas à avaliação de políticas públicas, compreendendo a complexidade e o caráter multidimensional da atividade avaliativa. Como objetivos específicos, o caso também visa mobilizar em sala de aula os conceitos de desenvolvimento local, tecnologia apropriada e continuidade/descontinuidade de políticas públicas, familiarizando os estudantes com as respectivas literaturas.

\section{Alternativas Conceituais para Análise do Caso}

Sem prejuízo de outras possíveis, sugere-se um conjunto de referências conceituais que pode ser explorado em aula com apoio do caso. Não é objetivo aqui apresentar os conceitos de maneira completa, mas apenas sugerir perspectivas e indicar bibliografia para aprofundamento.

\section{Desenvolvimento local}

Desenvolvimento é um termo extremamente difundido na literatura econômica e de políticas públicas e possui inúmeras conceituações. Essa diversidade se reflete em uma variedade de adjetivos que foram sendo criados para acompanhá-lo: local, sustentável, territorial, sustentado, integrado, democrático, participativo, etc. (MARTINS; VAZ; CALDAS, 2010). Dentro desse espectro, desenvolvimento local (ou territorial) costuma referir-se à capacidade dos atores de um dado território de utilizarem recursos ali disponíveis, colocando-os a serviço da geração e apropriação de renda e riqueza.

Benko e Pecqueur (2001), assim como Pecqueur (2005a, 2005b), ao refletirem sobre o desenvolvimento local, criam uma tipologia que classifica os fatores de produção em recursos e ativos. Recursos são fatores a explorar, a organizar-se, ou mesmo a revelar-se em um dado território. À medida em que esses fatores são efetivamente utilizados, eles mudam de estatuto e se tornam ativos. Nessa ótica, a dimensão econômica do desenvolvimento está intrinsecamente ligada às dimensões ambiental, cultural, política e social. São estas que influenciam a ativação de recursos territoriais (SANTOS; RODRÍGUEZ-GARAVITO, 2006).

Esta perspectiva pode ser útil para comparar as situações de Dona Josefa e Aninha, atendidas respectivamente pelo Programa 1 Milhão de Cisternas (P1MC) e pelo Programa Água para Todos. Se por um lado ambos programas se baseiam na transferência de um ativo (a cisterna), o primeiro também investe intensamente na utilização (ativação) de um recurso presente no território (capital social) e também incentiva o desenvolvimento de novos recursos locais na medida em que promove 0 aprendizado e a apropriação de técnicas construtivas, por exemplo. No segundo, estes recursos locais permanecem inalterados. 


\section{$\underline{\text { Tecnologia apropriada }}$}

Pode-se dizer que o conceito de tecnologia apropriada nasceu na Índia, nos anos 1920 e 1930, embora a expressão tecnologia apropriada, que hoje o designa, só tenha surgido algumas décadas depois.

A ideia surgiu no bojo do movimento de contestação liderado por Mahatma Gandhi para libertação daquele país, então colônia britânica (DAGNINO; BRANDÃO; NOVAES, 2004). 0 exemplo mais conhecido foi o resgate proposto por Gandhi da roca de fiar, um tear manual tradicional da cultura indiana. Por meio dessa tecnologia tradicional, as famílias indianas poderiam produzir seu próprio vestuário, substituindo o consumo de tecidos industriais ingleses. De forma semelhante, Gandhi liderou em 1930 a Marcha do Sal, um movimento de desobediência civil destinado a mostrar que os indianos não precisariam pagar pelo sal industrializado, uma vez que cada cidadão seria capaz de extrair da água do mar o sal para seu consumo.

Cerca de 40 anos mais tarde, as ideias de Gandhi tiveram forte influência no pensamento de autores como Herrera $(1973,1981)$, que cunhou a expressão tecnologia apropriada. Na mesma época também surgem outras designações que compartilham a mesma ideia central, como tecnologia branda (DICKSON, 1973) e tecnologia intermediária (SCHUMACHER, 1973), e mais recentemente tecnologia social. Para Herrera, a tecnologia está diretamente relacionada a um projeto político de sociedade: ela será melhor (mais apropriada) ou pior para a resolução de problemas locais, dependendo do seu grau de exogenia e da utilização que promove de recursos locais.

Em suas diferentes variantes, o conceito se aplica a tecnologias ou técnicas produtivas de fácil implantação no mundo em desenvolvimento, as quais se oferecem como alternativa de baixo custo a tecnologias industriais exógenas intensivas em capital. Tecnologias apropriadas são aplicáveis em pequena escala, são facilmente transferíveis e não exigem altos investimentos, na medida em que utilizam de forma intensiva mão de obra e recursos locais, na resolução de problemas econômicos e geração de bem-estar.

$\mathrm{Na}$ análise deste caso, o conceito de tecnologia apropriada resulta útil para contrastar as tecnologias que foram oferecidas a Dona Josefa (cisterna de placas de cimento) e a Aninha (e cisterna de poliuretano).

\section{Continuidade e descontinuidade de políticas públicas}

A descontinuidade de políticas públicas, entendida como a interrupção de projetos ou programas como resultado de um viés político, em geral desprezando as possíveis qualidades ou méritos daquilo que está sendo descontinuado, é um fenômeno muitas vezes (mas não necessariamente) ligado à transição entre governos. Embora considerada indesejável, ela está ligada à alternância de poder que faz parte da rotina democrática (NOGUEIRA, 2006).

Segundo Caldas e Ávila (2013), o problema da continuidade ou descontinuidade de políticas públicas admite gradações, e seu debate pode ser desdobrado em dois níveis: 0 da implementação e 0 da construção discursiva da política. Políticas que continuam são, por exemplo, aquelas que no período de transição entre um governo e outro são consideradas pelo novo governo como políticas de Estado. Nesse caso, pode ocorrer que, embora haja a manutenção da implementação da política (com seus objetivos, seu público específico, seus instrumentos e seus parâmetros), ocorra uma ruptura ou reconstrução do discurso sobre a mesma. Caso diametralmente oposto é quando, apesar da continuidade discursiva, os elementos constitutivos da política são radicalmente alterados.

Na situação retratada pelo caso, cabe discutir se até que ponto a transição entre o Programa 1 Milhão de Cisternas e o Programa Água Para Todos pode ser caracterizada como uma descontinuidade de política pública. Embora os dois programas tenham o mesmo público destinatário, a mesma meta (instalar 1 milhão de cisternas) e em certa medida o mesmo artefato (cisterna), verifica-se um deslocamento de atores e uma mudança no modo de operar a política.

\section{Avaliação de políticas públicas}

Avaliação, segundo os dicionários, é o ato de atribuir valor ou importância a alguma coisa. Quando aplicada a uma política pública, a avaliação é um instrumento de gestão que subsidia decisões concernentes à continuidade da política ou a aperfeiçoamentos necessários, a partir da emissão de juízos não arbitrários sobre os resultados alcançados em termos de eficácia, eficiência e/ou efetividade. 
Fenômenos sociais são por natureza complexos e multifacetados, o que exige que sua avaliação seja multidimensional. É preciso decompô-los em um conjunto ou variáveis, bem como selecionar os indicadores a serem utilizados para cada uma delas (DEPONTI; ECKERT; AZAMBUJA, 2002). A seleção dessas variáveis e indicadores, porém, não é neutra: ao contrário, responde ao interesse de quem avalia. Se se levar em conta que uma política pública é uma intervenção na realidade social, que afeta e articula sujeitos e grupos sociais que detêm interesses e expectativas diversos, esta característica de não neutralidade da avaliação se acentua. A avaliação de políticas públicas envolve necessariamente duas dimensões - a técnica e a política -, sendo que a segunda não é passível de ser evitada ou ignorada (SILVA, 2008).

Diversos autores, entre eles Silva (2008) e Trevisan e Van Bellen (2008), descrevem diferentes abordagens teórico-metodológicas para avaliação de políticas públicas. De forma geral é possível dizer que abordagens mais tradicionais de avaliação tendem a centrar-se em aspectos tangíveis e facilmente quantificáveis, e seu foco central é a verificação, ex post, do cumprimento de objetivos quantitativos previamente definidos. Assim, um programa de política pública será tão bem avaliado quão próximo estiverem seus resultados de uma meta quantitativa previamente estabelecida.

Esta forma mais ortodoxa ou tradicional de avaliação, no entanto, encontra limitações. Dificilmente, por exemplo, ele é capaz de fornecer ou indicar correções de rumo à política, restringindo-se a acusar o alcance ou não de uma meta ou conjunto de metas inicial. Tampouco aufere possíveis outros efeitos da política avaliada que não aqueles antevistos pelos formuladores e incorporados às metas: benefícios imprevistos não são objeto de medição, e não entram na avaliação da política. Para Silva (2008), "a principal limitação da abordagem quantitativa é a impossibilidade de apreender os fenômenos sociais nas suas múltiplas determinações, por se restringir a medir resultados referentes a uma variável preestabelecida, desconsiderando outras variáveis contextuais" (p.163).

Para além desta forma de avaliação, contudo, existem abordagens e instrumentos mais qualitativos. De acordo com Silva (2008), "procedimentos de natureza quantitativa, quando complementados com outras técnicas e procedimentos de natureza qualitativa, podem ser adequados e pertinentes para o desenvolvimento da avaliação de políticas" (p.163, grifo nosso). Entre estas técnicas e procedimentos qualitativos de pesquisa avaliativa, a autora elenca a observação participante, a história oral, as histórias de vida e o estudo de casos, entre outras técnicas que envolvam a efetiva interação entre o avaliador e os sujeitos da política.

As histórias de vida e a observação participante podem identificar benefícios gerados pelo projeto que não estão/estavam entre os objetivos e metas inicialmente propostos. Muitas vezes, os referidos objetivos e metas não foram atingidos, mas outros ganhos e benefícios foram alcançados (ainda que não identificados e requeridos inicialmente pelo projeto).

A organização social decorrente da implementação de alguma política pública muitas vezes não é identificada como objetivo e mensurada como meta. No entanto, o fato de um agente (um indivíduo) participar de um processo político ou de um processo de produção/implementação de política pública pode ter efeito muito valioso tanto no curto quanto no longo prazo, pois pode capacitá-lo a mobilizar e/ou liderar grupos nas mais variadas atividades. Neste caso, trata-se de valorizar o que Hirschman (1987) chamou de princípio da conservação e mutação da energia social.

No que diz respeito à aplicação do caso, a relevância deste debate decorre do fato de que a decisão do Governo Federal de abandonar o Programa 1 Milhão de Cisternas e substituí-lo pelo Programa Água para Todos se baseou apenas em um critério quantitativo (não cumprimento da meta inicial de um milhão de cisternas em cinco anos), sem levar em conta outras dimensões possíveis, que teriam sido capados por avaliação qualitativa.

\section{Plano de aula sugerido}

0 roteiro a seguir se baseia na experiência de uso do caso por ambos os autores, que o vêm aplicando com sucesso em aulas de graduação. Embora tenha sido testado apenas na graduação, acredita-se que possa ser aplicado sem alterações significativas também em cursos de especialização e mestrado profissional.

O roteiro supõe que os estudantes já tenham sido expostos à literatura supramencionada de avaliação de políticas públicas, desenvolvimento local, tecnologia apropriada e continuidade/descontinuidade de políticas públicas. Nesse sentido, a aplicação aqui sugerida objetiva incentivar os alunos a mobilizar conceitos previamente estudados, muito mais do que a tomar contato com eles pela primeira vez.

Para melhor aproveitamento do tempo de aula, sugere-se que os estudantes tenham lido o caso com 
antecedência. Alternativamente, pode-se reservar um tempo no início da sessão, não inferior a 20 minutos, para que os alunos façam a leitura in loco. As etapas do roteiro foram dimensionadas pensando em uma sessão com duração de aproximadamente 90 minutos.

\section{Etapa 1 - Aquecimento (20 minutos)}

Pode-se iniciar a discussão do caso sugerindo que algum aluno o resuma para a classe, expressando em suas palavras a situação vivenciada por Dona Josefa, de um lado, e por Aninha, do outro. Outros participantes devem ser convidados a ajudá-lo, lembrando aspectos que possam ter sido deixados de lado. Isso ajudará a classe a relembrar e organizar os fatos do caso.

A depender do tempo disponível, esta etapa poderá ser complementada por uma breve discussão sobre as políticas públicas de combate à seca e à convivência com ela no semiárido. Para tanto, o professor poderá apoiar-se, por exemplo, em Passador e Passador (2010), ou em Travassos, Souza e Silva (2013), que analisam a questão sob perspectiva histórica.

Outra possibilidade é explorar conexões com obras literárias, filmes ou músicas que retratem a problemática da pobreza e da seca no semiárido. Alguns exemplos de obras que podem ser lembradas são as seguintes:

- Na literatura: Vidas Secas (romance de Graciliano Ramos), O Quinze (romance de Rachel de Queiroz), Morte e Vida Severina (poema de João Cabral de Melo Neto), João Boa-Morte (poema de Ferreira Gullar);

- No cinema: Vidas Secas (Nelson Pereira dos Santos, 1963), Cinema, Aspirinas e Urubus (Marcelo Gomes, 2005);

- Na música: Vozes da Seca (Luiz Gonzaga), Último Pau de Arara (Luiz Gonzaga), Funeral de um Lavrador (Chico Buarque).

\section{Etapa 2 - Debate preliminar (30 minutos)}

Nesta etapa, os alunos deverão ser chamados a tomar uma posição crítica, comparando os dois programas de política pública. Para tanto, sugere-se tomar como ponto de partida da discussão o parágrafo final do caso: "Aninha ficou contente. A cisterna não era igual à da madrinha, mas a não ser pela aparência e pelo material de que era feita, ela parecia ser exatamente a mesma coisa."

Retomando esse trecho final, o professor poderá convidar os alunos a se posicionarem em relação a ele: será que a avaliação de Aninha está correta? As cisternas instaladas na sua casa e na da madrinha são mesmo, na prática, a mesma coisa?

Vale observar que o objetivo do debate não é que a classe alcance um consenso ou encontre uma resposta correta ou conclusiva. Ao contrário, o objetivo é comparar os dois programas, identificando os atores envolvidos em cada um deles, seus respectivos objetivos e interesses, confrontando prós e contras.

Dependendo da quantidade de participantes e da disponibilidade de tempo, pode-se dividir a sala em pequenos grupos (preferencialmente com três a cinco componentes cada um), que discutirão internamente e, em seguida, apresentarão ao restante da classe a sua avaliação.

\section{Etapa 3 - Aprofundamento da discussão (40 minutos)}

Nesse momento, a ideia é fazer com que a discussão da etapa anterior avance para um maior nível de detalhamento, com o objetivo de conectar a discussão com as alternativas conceituais de análise sugeridas na seção anterior. Para tanto, sugere-se que o professor conduza uma discussão plenária, que poderá se basear nas quatro questões a seguir:

1. Como os dois programas podem ser comparados, no que se refere à mobilização de recursos disponíveis no território? 
Esta primeira pergunta se destina a mobilizar conceitos de desenvolvimento local/territorial. A resposta passa pela percepção de que, embora os dois programas se baseiem na transferência de um ativo (a cisterna), o P1MC o faz utilizando (e ativando) uma variedade de recursos locais - capital social, aprendizado coletivo, compra local de materiais de construção - que não são explorados pelo Programa Água para Todos. Desta forma, os dois programas se diferenciam pelo grau - significativamente maior no primeiro do que no segundo - com que são capazes de gerar desenvolvimento local/territorial conceituado conforme Pecqueur (2005a, 2005b) e Benko e Pecqueur (2001).

2. Como se pode comparar os dois tipos de cisterna, fornecidos por programas diferentes, no que se refere à autonomia para conviver com a seca?

A pergunta se destina a mobilizar a discussão sobre tecnologia apropriada. A resposta consiste em mostrar que a tecnologia da cisterna de placas de concreto possui características desse tipo de tecnologia que estão ausentes no caso da cisterna de poliuretano. A cisterna industrializada de Aninha é baseada em uma tecnologia exógena intensiva em capital e não reprodutível, logo geradora de dependência, ao passo que a de Dona Josefa é uma tecnologia facilmente transferivel, aplicável em pequena escala e que exige baixo investimento, portanto mais compatível com as conceituações de Herrera $(1973,1981)$, Schumacher (1973) e Dickson (1973).

3. Apesar da mudança de nome, de Programa 1 Milhão de Cisternas para Programa Água para Todos, pode-se dizer que houve continuidade na política pública?

Trata-se aqui de exercitar a discussão sobre continuidade/descontinuidade de políticas públicas. A resposta admite diferentes opiniões ou interpretações, e não há a necessidade de que a classe chegue a um consenso. Ainda assim, é possivel argumentar, a partir de Caldas e Ávila (2013), que houve continuidade na construção discursiva da política, e uma clara descontinuidade no plano objetivo. A essência da política se altera junto com o tipo de cisterna - da autoconstruída, baseada em tecnologia apropriada, para a industrializada, intensiva em capital -, embora tal mudança não tenha se refletido no discurso governamental.

4. O não alcance pelo P1MC de sua meta quantitativa é suficiente para emitir um juízo sobre seus resultados?

A questão tem o propósito de incentivar a discussão sobre diferentes abordagens de avaliação de políticas públicas (SILVA, 2008; TREVISAN; VAN BELLEN, 2008), e sua resposta passa pelo reconhecimento de que comparações entre o P1MC e o Programa Água Para Todos com base exclusivamente na meta quantitativa são necessariamente parciais, deixando de captar dimensões relevantes do fenômeno avaliado. Se por esse indicador o P1MC se mostra mal avaliado, o resultado pode não ser tão ruim numa avaliação qualitativa, centrada, por exemplo, na experiência dos sujeitos atendidos pela política. Como observam, por exemplo, Deponti et al. (2006) e Silva (2008), a avaliação é, antes de tudo, uma atividade política, e a escolha de critérios, métricas ou indicadores para a prática avaliativa está em boa medida a serviço de quem avalia.

\section{REFERÊNCIAS}

BENKO, G.; PECQUEUR, B. Os recursos de territórios e os territórios de recursos. Geosul, Florianópolis, v.16, n.32, p.31-50, jul./dez.2001.

CALDAS, E. L.; ÁVILA, M. L. Continuidade de políticas públicas e o caso do Programa Nacional de Alimentação Escolar (PNAE). Revista Espaço Acadêmico, Maringá, v.13 n.148 p.77-84, set. 2013.

DAGNINO, R.; BRANDÃO, F. C.; NOVAES, H. T. Sobre o marco analítico conceitual da tecnologia social. In: LASSANCE JR., A. E. et al. (Orgs). Tecnologia social: uma estratégia para o desenvolvimento. Rio de Janeiro: 
Fundação Banco do Brasil, 2004, p.15-66.

DEPONTI, C. M.; ECKERT, C.; AZAMBUJA, J. L. B. Estratégia para a construção de indicadores para avaliação de sustentabilidade e monitoramento de sistemas. Agroecologia e Desenvolvimento Sustentável, v.3, n.4, p.4452, out./dez 2002.

DICKSON, D. Alternative technology and the politics of technical change. Glasgow: Fontana/Collins, 1974.

HERRERA, A. O. The generation of technologies in rural areas. World Development, Washington, v. 9 n.1, p.2135, jan. 1981,

HERRERA, A. O. La creación de tecnología como expresión cultural. In: Nueva Sociedad, Santiago, n 8-9, p. 5870, set./dez.1973.

HIRSCHMANN, A. O. Progresso em coletividade: experiências de base na América Latina. Nova York: Fundacão Interamericana, 1987.

MARTINS, R. D.; VAZ, J. C.; CALDAS, E. L. A gestão do desenvolvimento local no Brasil: (des)articulação de atores, instrumentos e território. Revista de Administração Pública, Rio de Janeiro, v. 44, n. 3, p. 559-590, maio/jun. 2010. DOl: http://dx.doi.org/10.1590/S0034-76122010000300002

NOGUEIRA, F. A. Continuidade e descontinuidade administrativa em governos locais: fatores que sustentam a ação pública ao longo dos anos. Dissertação (mestrado em Administração Pública e Governo). São Paulo: Fundação Getulio Vargas, 2006.

PASSADOR, C. S.; PASSADOR, J. L. Apontamentos sobre as políticas públicas de combate à seca no Brasil: cisternas e cidadania? Cadernos Gestão Pública e Cidadania, São Paulo, v. 15, n.56, p.65-86, 2010. DOI: http://dx.doi.org/10.12660/cgpc.v15n56.3203

PECQUEUR, B. Les territoires créateurs de nouvelles ressources productives: le cas de l'agglomération grenobloise. Geographie, économie, societé. Vol.7, n.3, p. 255-268, 2005a, DOI: 10.3166/ges.7.255-268

PECQUEUR, B. O desenvolvimento territorial: uma nova abordagem dos processos de desenvolvimento para as economias do sul. Raízes, Campina Grande, v. 24, n. 1 e 2, p.10-22, jan./dez,2005b.

SCHUMACHER, E. F. Small is beautiful: technology as if people mattered. Londres: Blond and Briggs, 1973

SILVA, M. O. S. Avaliação de políticas e programas sociais: uma reflexão sobre o conteúdo teórico e metodológico da pesquisa avaliativa. In: SILVA, M.O.S. (Org.), Pesquisa avaliativa: aspectos teórico-metodológios. São Paulo: Veras, 2008, p.15-42.

TRAVASSOS, I. S.; SOUZA, B. I.; SILVA, A. B. Secas, desertificação e políticas públicas no semiárido nordestino brasileiro. Okara Geografia em Debate, João Pessoa, vol.7 n.1, p. 147-164, jan./jun. 2013.

TREVISAN, A. P.; VAN BELLEN, H. M. Avaliação de políticas públicas: uma revisão teórica de um campo em construção. Revista de Administração Pública, Rio de Janeiro, vol. 42, n.3, p.529-550 maio/jun. 2008. 